Terakreditasi Sinta 3 | Volume 3 | Nomor 4 (Special Issue) | Tahun 2020 | Halaman 435-444

P-ISSN 2615-725X | E-ISSN 2615-8655

http://diglosiaunmul.com/index.php/diglosia/article/view/165

\title{
PILIHAN HIDUP TOKOH UTAMA ZARAH AMALA DALAM NOVEL SUPERNOVA EPISODE: PARTIKEL KARYA DEE LESTARI: KAJIAN FEMINISME LIBERAL
}

\author{
The Life Choices of Zarah Amala in "Supernova Episode: Partikel" by Dee Lestari: \\ Liberal Feminism Studies
}

\author{
Wahid Tawaqal ${ }^{1, *}$, Mursalim ${ }^{2}$, dan Irma Surayya Hanum ${ }^{3}$ \\ ${ }^{1,2,3}$ Program Studi Sastra Indonesia, Fakultas Ilmu Budaya, Universitas Mulawarman \\ 1,*Pos-el korespondensi: wahidtawaqa108@gmail.com \\ ${ }^{2}$ Pos-el: mursalim_unmul@ymail.com \\ ${ }^{3}$ Pos-el: saqilahanum@yahoo.co.id
}

\begin{abstract}
This research raises the topic of liberal feminism Zarah Amala, the main character in the Supernova Episode: Partikel by Dee Lestari. The purpose of this research is to describe the liberal feminist attitude of the main character and at the same time describe the impact of the life choice of the main character on the main additional character. This research is a type of library research. The discussion of liberal feminism studies uses the theory developed by Wolf (1997), namely the Feminism of Power and the theory of figures and characterizations. Zarah practices liberal feminism in the form of Power Feminism, among others: (1) observing power against women, (2) firmness in choice, (3) desire that women are not destitute, (4) tolerant, (5) women's competition, and (6)) have strong confidence. The figures affected by the liberal feminism idea adopted by Zarah were a group of main additional figures: (1) Firas: Zarah gives loyalty so that her father does not feel alone; (2) Aisyah: Zarah made Aisyah feel depressed because of the quarrel they were maintaining; (3) Abah Hamid: Zarah is no longer considered a grandchild because of her very different views; (4) Hara: Zarah has a stake in the character of her mature and stoic sister; (5) Ibu Inga: Zarah becomes a foster mother of an orangutan. (6) Paul: Zarah makes Paul fall in love; (7) Simon: Zarah makes Simon busier than usual; (8) Koso: Zarah becomes a loyal friend; and (9) Storm: Zarah gives her virginity to Storm.
\end{abstract}

Key words: main character, Zarah character, liberal feminism

\begin{abstract}
Abstrak: Penelitian ini mengangkat topik feminisme liberal Zarah Amala, tokoh utama dalam Supernova Episode: Partikel karya Dee Lestari. Tujuan penelitian ini mendeskripsikan sikap feminis liberal tokoh utama dan sekaligus mendeskripsikan dampak pilihan hidup tokoh utama terhadap tokoh tambahan utama. Penelitian ini berjenis penelitian kepustakaan. Pembahasan kajian feminisme liberal menggunakan teori yang dikembangkan Wolf (1997), yaitu feminisme kekuasaan serta teori tokoh dan penokohan. Zarah mempraktikkan feminisme liberal dalam bentuk feminisme kekuasaan antara lain: (1) mengamati kekuatan yang melawan perempuan, (2) teguh pada pilihan, (3) keinginan agar perempuan tidak melarat, (4) toleran, (5) persaingan perempuan, dan (6) memiliki keyakinan kuat. Tokoh yang terkena dampak dari ide feminisme liberal yang dianut Zarah adalah kelompok tokoh tambahan utama, antara lain: (1) Firas: Zarah memberi kesetian agar ayahnya tidak merasa sendiri; (2) Aisyah: Zarah membuat Aisyah merasa tertekan karena pertengkaran yang mereka pelihara; (3) Abah Hamid: Zarah tidak lagi dianggap sebagai cucu karena pandangannya yang sangat berbeda; (4) Hara: Zarah memiliki andil atas sifat adiknya yang dewasa dan tabah; (5) Ibu Inga: Zarah menjadi ibu asuh dari orang utan; (6) Paul: Zarah membuat Paul jatuh hati; (7) Simon: Zarah membuat Simon menjadi lebih sibuk daripada biasanya; (8) Koso: Zarah menjadi teman yang setia; serta (9) Storm: Zarah memberikan keperawanannya untuk Storm.
\end{abstract}

Kata kunci: tokoh utama, tokoh Zarah, feminisme liberal 


\section{A. PENDAHULUAN}

Wacana kesetaraan antara perempuan dan laki-laki semakin terbuka untuk dibicarakan. Emansipasi sebagai sebuah kesadaran tumbuh dari zaman ke zaman. Di Indonesia kesadaran emansipasi telah ditanamkan sejak dini. Di bangku sekolah kesadaran emansipasi itu dibentuk melalui serangkaian acara setiap 21 April atau dikenal sebagai Hari Kartini. Dalam peringatan Hari Kartini para murid diajarkan untuk memahami konsep kesetaraan bahwa tidak ada perbedaan hak antara laki-laki dan perempuan. Kesetaraan diajarkan sebagai cita-cita perjuangan Kartini yang semasa hidupnya menyaksikan hak perempuan dikekang oleh kolonial Belanda dan tradisi Jawa pada masa itu. Meski sudah berkembang dibandingkan pada zaman Kartini, namun kesetaraan tetap tidak pernah seutuhnya menjadi milik perempuan. Perempuan tidak sepenuhnya bebas dalam menggunakan otoritasnya. Sebagai contoh, pilihan hidup perempuan sangat mungkin digugat dan mendapatkan justifikasi dari lingkungan sekitarnya. Mulai dari orang tua, keluarga, hingga teman dekat.

Perempuan kerap menjadi objek yang dipersalahkan, bahkan ketika perempuan menjadi korban. Misalnya dalam kasus pemerkosaan atau pelecehan seksual yang korbannya adalah perempuan, tekanan justru lebih banyak dialami oleh korban. Perempuan sering kali dituduh sebagai pihak yang salah entah karena cara berpakaian atau kondisi yang dianggap mengundang pelaku untuk memerkosa. Dalam hal ini menyalahkan korban menjadi lebih mudah, daripada berpikir pelaku yang berniat jahat. Kasus pelecehan seksual yang terjadi pada Agni, mahasiswi Universitas Gadjah Mada merupakan contoh bagaimana korban pelecehan seksual sangat rentan dipersalahkan dan sulit memperoleh keadilan. Komentar perempuan seperti ikan asin yang mengundang kucing (Balairung, 2018) merupakan salah satu bentuk penghakiman yang diterima perempuan, meski sejatinya mereka adalah korban. Hal ini menegaskan adanya ancaman dan bahwa kebebasan yang ingin dimiliki perempuan belum dapat diperoleh secara utuh.

Kondisi tersebut yang ditentang para feminis liberal, mereka beranggapan perempuan harus mempunyai kebebasan. Namun untuk memperoleh kebebasan bukan sesuatu yang mudah, khususnya perempuan di Indonesia yang hidup dengan batasan norma. Karya sastra kemudian muncul sebagai pilihan berekspresi. Karya sastra pada dasarnya merupakan cerminan atas kondisi sosial masyarakat yang terjadi di sekitarnya. Para pengarang menggunakan karya sastra untuk menyajikan persoalan dan kritik yang dikemas melalui imajinasi cerita. Tujuan sebuah isu diangkat dalam karya sastra adalah untuk menanamkan kesadaran atas isu tersebut ataupun mencoba menawarkan sudut pandang yang lain. Karya sastra berjudul Supernova Episode: Partikel yang ditulis oleh Dee Lestari menunjukkan sikap tersebut. Novel ini mengangkat isu serius tentang hakikat seorang perempuan. Novel ini menceritakan tentang tokoh utama perempuan bernama Zarah yang menginginkan hak dan kebebasan dalam menentukan pilihan hidupnya. Sebagai seorang perempuan ia dibebani dengan beragam konsensus yang hadir di lingkungan sekitarnya.

Zarah memutuskan untuk keluar dari rumah dan menentukan hak atas pilihan hidupnya. Tindakan Zarah sejalan dengan pemikiran liberal yang melihat hak sebagai prioritas di atas kebaikan. Jaggar mengamati pemikiran politis liberal mempunyai konsepsi atas sifat manusia, yang menempatkan keunikan manusia dalam kapasitasnya untuk bernalar (Tong, 1998, hal. 15). Salah satu perwujudan 
paham dari feminisme liberal adalah apa yang disebut dengan Feminisme Kekuasaan. Dalam novel Supernova Episode: Partikel karya Dee Lestari, Zarah menolak keadaan perempuan yang tidak produktif, Zarah menginginkan kebebasan dalam menentukan pilihan. Hal ini membuat keluarga besar Zarah mengganggap ia sebagai pemberontak yang mengikuti jejak Firas. Kebebasan yang ingin Zarah peroleh ini menimbulkan dampak yang dirasakan oleh orang-orang yang berada di sekelilingnya (tokoh tambahan utama).

Berbeda dengan penelitian novel Supernova Episode: Partikel karya Dee Lestari yang pernah dibuat sebelumnya, penelitian ini akan fokus pada pilihan hidup yang diambil tokoh utama Zarah. Temuan masalah yang diungkap adalah: Pertama, bagaimana feminis liberal tercermin dalam diri Zarah? Kedua, bagaimana dampak pilihan hidup yang diambil Zarah terhadap tokoh tambahan utama dalam novel Supernova Episode: Partikel karya Dee Lestari? Penelitian ini bertujuan untuk menjelaskan sikap feminis liberal Zarah dan sekaligus mendeskripsikan dampak pilihan hidup Zarah kepada tokoh tambahan utama. Hasil dari penelitian ini diharapkan dapat menumbuhkan serta menambah wawasan tentang studi sastra, khususnya yang berkaitan dengan feminisme liberal. Selain itu, dapat memberi referensi tambahan mengenai penerapan teori tokoh dan penokohan. Secara praktis penelitian ini dapat menjadi rujukan untuk penelitian yang membahas feminisme liberal dalam karya sastra. Para pembaca novel Supernova Episode: Partikel karya Dee Lestari juga dapat mendalami amanat dari kisah Zarah. Penelitian ini diharapkan berguna dalam meningkatkan apresiasi masyarakat terhadap sebuah karya sastra.

Penelitian yang menjadikan novel Supernova Episode: Partikel karya Dee Lestari sebagai objek penelitian, telah beberapa kali dilakukan. Hasil kajian pustaka menunjukkan, tiga penelitian telah membahas novel Supernova Episode: Partikel karya Dee Lestari. Pertama, penelitian Nima Lestianingsih (2013) berjudul Analisis Nilai-Nilai Pendidikan Karakter Pada Novel Supernova: Partikel Karya Dewi Lestari, Fakultas Keguruan dan Ilmu Pendidikan, Universitas Sebelas Maret. Lestianingsih menemukan bahwasanya nilai karakter yang terdapat pada tokoh novel Supernova Episode: Partikel karya Dee Lestari berjumlah sebanyak dua puluh. Antara lain, yaitu mandiri, pantang menyerah, rasa ingin tahu, kesetiakawanan, peduli dan bertanggung jawab terhadap pemeliharaan tumbuhan, binatang, dan lingkungan alam sekitar, cinta lingkungan, kerja keras, keberanian, religius, percaya diri, bertanggung jawab, rela berkorban, gigih, rajin, toleran, tidak pernah ingkar janji, santun, tabah, kesadaran diri, serta kasih sayang.

Kedua, penelitian Kartika Nurul Nugrahini (2014) dengan judul Kepribadian dan Aktualisasi Diri Tokoh Utama dalam Novel Supernova Episode Partikel Karya Dewi Lestari (Tinjauan Psikologi Sastra), Fakultas Bahasa dan Seni, Universitas Negeri Yogyakarta. Dalam penelitian ini Nugrahini mengungkap Zarah sebagai tokoh utama menonjol dengan karakter yang cerdas, pemberontak, dan keras kepala. Konflik yang dihadapi Zarah berupa pertentangan batin yang membuat dia menjalani masa pelarian. Serta, aktualisasi diri yang dicari Zarah yaitu keinginannya untuk bisa menemukan Firas (ayahnya) kembali.

Ketiga, penelitian Scholastika Pratiwi Putri Nastiti (2017) Formasi Ideologi Dalam Novel Partikel Karya Dee Lestari: Perspektif Antonio Gramsci, Fakultas Sastra, Universitas Sanata Dharma. Melalui penelitiannya Nastiti menemukan ada lima ideologi dominan yang terdapat di dalam novel Supernova Episode: Partikel karya Dee Lestari, yaitu (1) liberalisme, (2) konservatisme, (3) teisme, 4) panteisme, dan (5) new age. 
Beberapa hasil studi yang sudah dikerjakan di atas berguna sebagai tinjauan untuk menunjang penelitian ini. Terdapat persamaan seperti objek penelitian yang digunakan serupa yaitu novel Supernova Episode: Partikel karya Dee Lestari. Penelitian ini akan berpusat pada pilihan tokoh utama Zarah dalam menjalani kehidupannya ditinjau menggunakan perspektif feminisme liberal yang dikembangkan oleh Wolf yaitu Feminisme Kekuasaan. Selain itu, mendeskripsikan tokoh dan penokohan yang akan digunakan sebagai bahan guna mengulas dampak pilihan hidup Zarah terhadap tokoh tambahan utama.

Feminisme liberal adalah turunan dari aliran pemikiran politik liberalisme. Rokhmansyah (2016, hal. 51) menjelaskan feminisme liberal beranggapan sistem patriarki dapat dihancurkan dengan cara mengubah sikap masing-masing individu, terutama sikap kaum perempuan dalam hubungannya dengan laki-laki. Kaum liberal setuju bahwa suatu masyarakat yang adil akan memungkinkan seorang individu untuk menunjukkan otonominya, dan juga untuk memuaskan dirinya. Menurut kaum liberal, "hak" harus diberikan sebagai prioritas di atas "kebaikan" (Tong, 1998, hal.16). Hak menjadi segalanya bagi kaum liberal, hak dilihat sebagai pilihan untuk memilih yang terbaik selagi itu tak merampas hak orang lain. Menurut Tong, prioritas seperti ini membela kebebasan beragama bahwa manusia memiliki hak untuk melaksanakan spritualitas yang diinginkannya, tanpa perlu ada unsur mutlak terhadap kehidupan yang bertuhan, bahwasanya hidup seperti itu lebih berharga daripada kehidupan yang tak bertuhan.

Friedan menyatakan pencapaian identitas diri, kesetaraan, dan bahkan kekuasaan politik, tidak mengartikan seorang perempuan berhenti mempunyai kebutuhan untuk mencintai dan dicintai oleh seorang laki-laki, atau tidak juga berarti bahwa perempuan berhenti merawat anak-anak mereka (Tong, 1998, hal. 40). Masalah yang membelit feminisme bukan hanya kesulitan membuat pesan-pesannya menembus tirai prasangka anti-feminis, tetapi masalah sudah ada dalam pesan-pesan itu sendiri (Wolf, 1997, hal. 199). Wolf mengurai masalah feminisme ini dengan membaginya ke dalam dua kelompok yakni Feminisme Kekuasaan dan Feminisme Korban. Wolf menjelaskan Feminisme Kekuasaan adalah paham yang mengemuka saat seorang perempuan mengais kekuasaan lewat jati diri ketidakberdayaan. Sementara Feminisme Korban memperlambat kemajuan perempuan, merintangi pengetahuan akan diri sendiri, dan bertanggung jawab atas sebagian besar pola pikir yang tidak konsisten, negatif, sauvinis, dan dalam segala hal regresif atau membawa kemunduran (Wolf, 1997, hal. 199).

Feminisme Korban telah mengurung gerakan perempuan; ia adalah apa yang seseorang lakukan tiap kali seseorang tersebut undur diri ke dalam tarikan status berdasarkan "keistimewaan feminin" dan bukannya harga manusia sebagai keseluruhan (Wolf, 1997, hal. 199). Feminisme Korban merupakan antitesis dari ide feminisme liberal. Sedangkan Feminisme Kekuasaan adalah kebalikannya, ingin melibatkan perempuan lebih banyak lagi. Wolf (1997, hal. 204) mengatakan ideologi yang dijunjung Feminisme Kekuasaan luwes dan inklusif, bersifat melingkupi. Feminisme Kekuasaan memiliki tradisi yang bertujuan untuk membawa perempuan mencapai "kekuasaan", sekaligus juga melepaskan mereka dari jebakan Feminisme Korban. Tradisi feminisme kekuasaan berjumlah 16 dan Wolf (1997, hal. 202-204).

(1) Mengamati dari dekat kekuatankekuatan yang melawan perempuan, hingga perempuan bisa menggunakan kekuatannya sendiri secara lebih efektif. 
(2) Mengetahui bahwa pilihan-pilihan yang diambil oleh perempuan bisa memengaruhi kehidupan orangorang di sekitarnya dan bisa mengubah dunia.

(3) Menyemangati perempuan agar mengklaim suara individual ketimbang melebur suaranya ke dalam kor kelompok atau jati-diri kolektif; sebab hanya pribadi-pribadi yang kuat yang bisa membentuk komunitas yang berkeadilan.

(4) Seksual tanpa apologi, tak merasa harus "minta izin" dari orang lain; memahami bahwa kesenangankesenangan yang "baik" akan menelurkan politik yang "baik".

(5) Mengejar kekuasaan dan menggunakannya secara bertanggung jawab, baik demi kepentingan perempuan sebagai pribadi-pribadi maupun untuk membuat dunia jadi lebih adil bagi orang-orang lain.

(6) Sadar bahwa kemelaratan tidaklah gemerlap. Ingin agar perempuan memperoleh uang, demi mencapai impian-impian kemandirian, dan demi keamanannya sendiri, sekaligus demi perubahan sosial.

(7) Mengakui ketertarikan perempuan akan "tanda tangan" dalam kehidupan; akan pengakuan dan ketenaran; akan ambisi. Maka perempuan bisa mencari "kredit" bagi dirinya sendiri serta memberi pengakuan yang sama pada orangorang lain yang mencapai sesuatu dalam hidup mereka.

(8) Tidak merasa sebal atau sirik atas prestasi perempuan lain; menganjurkan agar perempuan mengupayakan pencapaian apa pun yang diinginkan, agar bisa berbagi tanpa rasa iri.

(9) Bersikap toleran terhadap suara-suara yang berbeda tentang seksualitas dan penampilan di ranjang atau atas tubuhnya adalah urusannya sendiri dan orang-orang lain tak berhak turut campur.

(10) Mengetahui bahwa ambisi, agresi, persaingan, harapan atas otonomi dan pemisahan, serta perilaku merusak atau kasar adalah juga jati diri perempuan, sama dengan lelaki, keduanya hasil pembelajaran sekaligus watak dasar. Memahami bahwa laki-laki maupun perempuan harus belajar mengendalikan dorongan-dorongan itu; dan memandang perempuan sebagai manusia dewasa yang bermoral.

(11) Mencari 'dwi-bahasa'-isme (bilingualisme), yakni penggabungan apa yang terbaik dari pengetahuan tradisional dan komitmen-komitmen perempuan, dengan sumber daya tradisional lelaki.

(12) Punya keyakinan kuat, tapi selalu siap menyangsikannya bila ada alasan yang tepat, selalu skeptis dan terbuka, serta mempertanyakan semua kewenangan, termasuk kewenangan perempuan sendiri.

(13) Berpendapat bahwa baik lelaki maupun perempuan tidak memonopoli cacat dalam karakter manusia. Tidak menyerang lelaki sebagai sebuah gender, melainkan menggugat kekuasaan yang tidak proporsional yang dipegang oleh lakilaki. Dan memandang penilaian sosial "laki-laki lebih baik dari perempuan" sebagai penilaian yang keliru.

(14) Memiliki "jiwa berkelimpahan"menginginkan agar semua perempuan bergerak menyetarakan diri dengan yang di "atas", agar mereka memperoleh lebih banyak lagi. Percaya bahwa perempuan berhak untuk merasa kualitas-kualitas para bintang dan para ratu, dalam sensualitas dan kecantikan, bisa menjadi milik perempuan.

(15) Ingin agar semua perempuan menyatakan pendapat mereka sendiri. 
(16) Tahu bahwa membuat perubahan sosial tidaklah bertentangan dengan prinsip "gadis-gadis hanya ingin bersenang-senang". Motonya: "Jika aku tak bisa berdansa, itu bukan revolusiku."

\section{B. METODE}

Jenis penelitian yang digunakan adalah penelitian kepustakaan, dengan pendekatan penelitian berupa deksriptif kualitatif. Data penelitian ialah kutipan yang berasal dari sumber data novel Supernova Episode: Partikel karya Dee Lestari. Teknik pengumpulan data menggunakan teknik baca, simak, dan catat. Untuk tekni menganalisis data digunakan proses kegiatan berupa reduksi data, penyajian data, dan penarikan simpulan.

\section{PEMBAHASAN}

\section{Feminisme Liberal dalam Diri Tokoh Zarah Amala}

Pada dasarnya feminisme liberal memiliki pemahaman bahwa perempuan harus mempunyai kesadaran dan mau berjuang untuk menuntut hak mereka. Dengan kata lain, kelompok feminis liberal mendambakan sebuah kebebasan dan hak otonomi yang penuh bagi seorang perempuan dalam menjalani kehidupannya. Naomi Wolf, pemikir sekaligus seorang feminis liberal, membagi perspektif feminisme ke dalam dua golongan yaitu (1) Feminisme Kekuasaan, dan (2) Feminisme Korban. Feminisme Kekuasaan dicirikan lebih memiliki kekuatan dan kemampuan menggedor sebagai sebuah sikap perjuangan, sementara Feminisme Korban muncul dengan membawa pertentangan dari sikap tersebut. Dalam Feminisme Korban dan Feminisme Kekuasaan terdapat sejumlah tradisi yang menjadi sifat dari dua golongan feminisme ini. Tradisi ini digunakan sebagai indikator untuk mengelompokan feminsime mana yang dianut oleh seseorang. Jika seseorang itu memiliki paham feminisme liberal, maka ia akan condong pada karakter Feminisme Kekuasaan, karena tradisi di dalamnya banyak mendorong kepada hak dan kekuatan perempuan. Sementara Feminisme Korban merupakan antitesis dari ide liberal itu sendiri. Feminisme Korban justru membuat perempuan terlihat lemah.

Novel Supernova Episode: Partikel karya Dee Lestari berkisah tentang hidup tokoh utama perempuan bernama Zarah Amala. Keputusan dan pilihan yang diambil Zarah di dalam cerita kerap kali bertentangan dengan pendapat orang di sekitarnya. Di sini Zarah berusaha memperjuangkan sendiri haknya sebagai seorang perempuan. Hal ini bersinggungan dengan ide feminisme liberal yang diuraikan Wolf dalam tradisi Feminisme Kekuasaan. Terdapat 16 tradisi Feminisme Kekuasaan dan sebanyak 6 di antaranya dipraktikkan Zarah dalam novel Supernova Episode: Partikel karya Dee Lestari. Tradisi Feminisme Kekuasaan yang dilakukan Zarah sehingga membuatnya menjadi perempuan dengan sikap liberal, adalah antara lain: (1) mengamati kekuatan yang melawan perempuan, (2) teguh pada pilihan, (3) keinginan agar perempuan tidak melarat, (4) toleran, (5) persaingan perempuan, dan (6) memiliki keyakinan kuat. Bukti yang menyertai tradisi Feminisme Kekuasaan ini dapat dilihat dari pilihan hidup yang diambil Zarah. Misalnya ketika Zarah menyadari Abah Hamid sebagai kakeknya menginginkan adiknya yang baru dengan keadaan abnormal untuk mati. Di sini Zarah mempunyai keberanian dalam menyampaikan pendapat, kendati itu berbeda dari yang diinginkan keluarganya. Dengan cara seperti itu Zarah mengamati kekuatan yang melawan perempuan.

Zarah adalah perempuan yang teguh pada pilihan. Zarah lebih menyayangi sosok kontroversial seperti ayahnya, Firas daripada ibunya, Aisyah. Zarah berikrar akan mengikuti jejak ayahnya di dalam 
rumah sebagai seorang pemberontak. Ia memilih tinggal kelas demi menemani sahabatnya, Koso belajar. Zarah memutuskan untuk keluar dari rumah setelah bertengkar dengan ibunya. Ia memilih tinggal di Tanjung Puting, meninggalkan kehidupannya yang ada di Pulau Jawa. Keteguhan Zarah membawa dia sampai ke London untuk mencari ayahnya.

Sebagai perempuan Zarah mempunyai keinginan agar sesama perempuan tidak melarat. Itu dibuktikannya dengan membantu Koso belajar setelah tinggal kelas. Ada banyak perbedaan pandangan antara Zarah dengan keluarganya, namun hal itu membentuk Zara menjadi orang yang toleran. Zarah menerima perbedaan pandangannya dengan sang kakek dalam menyepakati agama. Zarah berpusat pada ambisi untuk menemukan ayahnya. Proses perjalanan itu membentuk Zarah menjadi perempuan yang berani. Satu waktu di tengah perjalanan di hutan bersama Paul dan Gary, sebagai satu-satunya perempuan Zarah mengusir dua ekor beruang yang menghadang jalan mereka. Wujud persaingannya sebagai seorang perempuan. Zarah juga tak sungkan menjalani kehidupan percintaan yang bebas bersama Storm. Selama 12 tahun dia melakukan pelarian demi mencari ayahnya memperlihatkan keyakinan Zarah yang kuat.

\section{Dampak Pilihan Hidup Zarah Amala terhadap Tokoh Tambahan Utama}

Sebuah cerita tidak akan bisa berjalan tanpa ada tokoh di dalamnya. Tokoh termasuk kunci dari cerita, karena tokoh bertugas sebagai pelaku yang menggerakkan situasi, alur, atau konflik yang ada di dalam cerita sehingga bisa berkembang. Nurgiyantoro (2010, hal. 176) mengatakan dilihat dari segi peranan atau tingkat pentingnya tokoh dalam sebuah cerita, selalu akan ada tokoh yang tergolong penting dan ditampilkan terusmenerus sehingga mendominasi cerita. Inilah yang disebut tokoh utama yaitu tokoh yang diutamakan penceritaannya di dalam novel. Tetapi, ada juga tokoh sebaliknya yang hanya muncul sesekali atau bahkan sekali di dalam cerita. Jenis tokoh ini dinamakan tokoh tambahan.

Pembedaan antara tokoh utama dan tokoh tambahan, menurut Nurgiyantoro (2010, hal. 178), tidak dapat dilakukan secara eksak. Pembedaan itu lebih bersifat gradasi, yang berarti masih perlu tinjauan mengenai kadar keutamaan antar tokoh utama dan tokoh tambahan. Maka dari itu pembagian tokoh ini masih bisa bertingkat: tokoh utama (yang) utama, utama tambahan, tokoh tambahan utama, tambahan (yang memang) tambahan.

Novel Supernova Episode: Partikel karya Dee Lestari sebagai sebuah cerita mempunyai puluhan tokoh yang hadir di dalam cerita. Pembagian porsi peran dan kepentingan antar tokoh di dalam cerita juga berbeda-beda. Novel Supernova Episode: Partikel karya Dee Lestari hanya memiliki satu tokoh utama yaitu Zarah Amala. Selebihnya merupakan tokoh tambahan yang berada di sekeliling kehidupan Zarah. Terdapat sembilan tokoh yang dikategorikan sebagai tokoh tambahan utama. Pada kelompok tokoh ini Zarah banyak memberikan dampaknya sebagai perempuan dengan sikap feminime liberal. Kesembilan tokoh itu adalah: (1) Firas, (2) Aisyah, (3) Abah Hamid, (4) Hara, (5) Dr. Inga, (6) Paul, (7) Simon, (8) Koso, dan (9) Storm.

Dampak yang ditimbulkan Zarah kepada sembilan tokoh tambahan utama ini berbeda-beda. Pertama, kepada Firas, Zarah memberi kesetian agar ayahnya tidak merasa sendiri. Kedua, bagi Aisyah, Zarah membuat Aisyah merasa tertekan karena pertengkaran yang mereka pelihara. Ketiga, untuk Abah Hamid, Zarah tidak lagi dianggap sebagai cucu karena pandangannya yang sangat berbeda. Keempat, kepada Hara, Zarah memiliki 
andil atas sifat adiknya yang dewasa dan tabah. Kelima, terhadap Ibu Inga, Zarah menjadi ibu asuh dari orang utan. Keenam, kepada Paul, Zarah membuat Paul jatuh hati. Ketujuh, untuk Simon, Zarah membuat Simon menjadi lebih sibuk daripada biasanya. Kedelapan, bagi Koso, Zarah menjadi teman yang setia. Kesembilan, untuk Storm, Zarah memberikan keperawanannya untuk Storm.

\section{PENUTUP}

Berdasarkan hasil dan pembahasan, maka dapat disimpulkan bahwa tokoh utama Zarah Amala dalam novel Supernova Episode: Partikel karya Dee Lestari menganut paham feminisme liberal. Keputusan dan pilihan yang diambil Zarah kerap bertentangan dengan pendapat orang di sekitarnya. Di sini Zarah berusaha memperjuangkan sendiri haknya sebagai seorang perempuan.

Wolf menyebutkan ada 16 tradisi dari feminisme kekuasaan, yang mana merupakan bagian dari kelompok feminisme yang mendasarkan idenya pada asas kebebasan atau liberal. Dari 16 tradisi feminisme kekuasaan itu, 6 di antaranya tercermin pada sikap Zarah dalam novel Supernova Episode: Partikel karya Dee Lestari. Tradisi feminisme kekuasaan tersebut antara lain: (1) mengamati kekuatan yang melawan perempuan, (2) teguh pada pilihan, (3) keinginan agar perempuan tidak melarat, (4) toleran, (5) persaingan perempuan, dan (6) memiliki keyakinan kuat. Paham liberal Zarah sebagai tokoh utama memberi dampak terhadap tokoh tambahan utama.

Di dalam novel Supernova Episode: Partikel karya Dee Lestari terdapat sembilan tokoh yang dikategorikan sebagai tokoh tambahan utama, di antaranya: (1) Firas: Zarah memberi kesetian agar ayahnya tidak merasa sendiri; (2) Aisyah: Zarah membuat Aisyah merasa tertekan karena pertengkaran yang mereka pelihara; (3) Abah Hamid: Zarah tidak lagi dianggap sebagai cucu karena pandangannya yang sangat berbeda; (4) Hara: Zarah memiliki andil atas sifat adiknya yang dewasa dan tabah; (5) Ibu Inga: Zarah menjadi ibu asuh dari orang utan; (6) Paul: Zarah membuat Paul jatuh hati; (7) Simon: Zarah membuat Simon menjadi lebih sibuk daripada biasanya; (8) Koso: Zarah menjadi teman yang setia; (9) Storm: Zarah memberikan keperawanannya untuk Storm.

\section{DAFTAR PUSTAKA}

Astuti, P., Mulawarman, W. G., Rokhmansyah, A. (2018). Ketidakadilan Gender terhadap Tokoh Perempuan dalam Novel Genduk Karya Sundari Mardjuki: Kajian Kritik Sastra Feminisme. Ilmu Budaya, 2(2), 105-114. http:/ /ejournals.unmul.ac.id/index.php/JB SSB/article/download/1046/965

Lestari, D. (2012). Supernova Episode: Partikel. Yogyakarta: Bentang Pustaka.

Lestianingsih, N. (2013). Analisis NilaiNilai Pendidikan Karakter pada Novel Supernova: Partikel Karya Dewi Lestari. Skripsi. Surakarta: Universitas Sebelas Maret.

Maudy, C. (2018). Nalar Pincang UGM atas Kasus Perkosaan. http://www.balairungpress.com/2 018/11/nalar-pincang-ugm-ataskasus-perkosaan/ (Diakses pada 9 Juli 2019).

Nastiti, S. P. P. (2017). Formasi Ideologi dalam Novel Partikel Karya Dee Lestari: Perspektif Antonio Gramsci. Skripsi. Yogyakarta: Universitas Sanata Dharma.

Nugrahini, K. N,p. (2014). Kepribadian dan Aktualisasi Diri Tokoh Utama dalam Novel Supernova Episode Partikel Karya Dewi Lestari (Tinjauan Psikologi Sastra). Skripsi. Yogyakarta: Universitas Negeri Yogyakarta. 
Nurgiyantoro, B. (2010). Teori Pengkajian Fiksi. Yogyakarta: Gadjah Mada University Press.

Rokhmansyah, A. (2016). Pengantar Gender \& Feminisme Pemahaman Awal Kritik Sastra Feminisme. Yogyakarta: Garudhawaca.

Sugihastuti \& Suharto. (2015). Kritik Sastra Feminis Teori dan Aplikasinya. Yogyakarta: Pustaka Pelajar.

Sukmadinata, S. N. (2005). Metode Penelitian Pendidikan. Bandung: Remaja Rosdakarya.

Swastyastu, G. P. (2017). Caca Mendadak Minta Maaf dan Ungkap Rahasia Mengapa Melepas Hijab, Netter: Nah Udah Sadar. Diperoleh dari https://solo.tribunnews.com/2017 /04/27/caca-mendadak-mintamaaf-dan-ungkap-rahasiamengapa-melepas-hijab-netter-nahudah-sadar (Diakses pada 9 Juli 2019).

Tong, R. (1998). Feminist Thought: Pengantar Paling Komprehensif kepada Arus Utama Pemikiran Feminis. Yogyakarta: Jalasutra.

Stanton, R. (2012). Teori Fiksi. Yogyakarta: Pustaka Pelajar.

Wolf, N. (1997). Gegar Gender Kekuasaan Perempuan Menjelang Abad 21. Yogyakarta: Pustaka Semesta Press.

Zed, M. (2014). Metode Penelitian Kepustakaan. Jakarta: Yayasan Obor Indonesia. 
